\title{
MUSCULOSKELETAL DISORDERS AND WORKING RISK FACTORS
}

\author{
Milan Tuček', Václav Vaněček² \\ ${ }^{1}$ Institute of Hygiene and Epidemiology, First Faculty of Medicine, Charles University, Prague, Czech Republic \\ ${ }^{2}$ Department of Orthopaedics, First Faculty of Medicine, Charles University and Military University Hospital, Prague, Czech Republic
}

\section{SUMMARY}

Objectives: The authors evaluate situation in the field of musculoskeletal disorders (MSDs) and working risk factors in the Czech Republic.

Methods: Analysis of selected data from the Czech National Registry of Occupational Diseases during 2008-2018, description of criteria for recognition of occupational MSDs and risk factors associated with MSDs.

Results: 6,152 cases of 6 selected recognized occupational musculoskeletal diseases represent $47 \%$ of all recognized occupational diseases. The main proportion formed diseases of peripheral nerves in the extremities in terms of compressive neuropathies due to long-term and stereotyped overload, diseases of tendons, tendon capsules or insertions of muscles or joints in the extremities due to long-term and stereotyped overload and diseases of peripheral nerves in the upper extremities in terms of ischaemic and compressive neuropathies due to work with vibrating tools and devices. The authors discussed decreasing trend of the exposure time in three main diagnoses and association of the incidence of MSDs with the risky work related to overload of the musculoskeletal system of the upper extremities.

Conclusions: Important factors for the prevention of MSDs are directly related to the technical provision of production, the organization of work and the regime of work and rest, the length of working hours and the setting of production standards, and generally to the work related stress.

Key words: musculoskeletal, occupational risk, vibration, overload, upper extremity, prevention

Address for correspondence: M. Tuček, Institute of Hygiene and Epidemiology, First Faculty of Medicine, Charles University, Studničkova 7, 12800 Prague 2, Czech Republic. E-mail: milan.tucek@lf1.cuni.cz

https://doi.org/10.21101/cejph.a6183

\section{INTRODUCTION}

Musculoskeletal disorders (MSDs) remain the most prevalent work-related health problem in the European Union (EU). Of all workers in the EU with a work-related health problem, $60 \%$ identify MSDs as their most serious issue. MSDs concern workers in all sectors and occupations. Besides the effects on workers themselves, they lead to high costs to enterprises and society. MSDs can be caused by many different (combinations of) factors. These include not only physical factors (whereby mechanical load applied to the musculoskeletal tissues can cause MSDs), but also organisational and psychosocial ones (1). In the Czech Republic, as in the most European countries, the frequency of MSDs has been continually increasing to the degree that they currently rank as the second most frequent cause of temporary working disability (2). The term "musculoskeletal disorders" is used in different countries in slightly different meanings; in the Czech Republic, we understand it as a general term covering a group of diseases affecting various parts of the locomotor system and originating from overuse/misuse of the locomotor system. An occupational disease is defined as a disease caused by the noxious effects of chemical, physical, biological, and other factors, provided that the disease originated under conditions described in the List of Occupational Diseases. According to the data from the Czech National Registry of Occupational Diseases, the MSDs represent with the proportion of $53 \%$ (649 in 2018, total number 1,222 occupational diseases) the most frequent category of occupational diseases in the Czech Republic, with carpal tunnel syndrome from overloading being the most frequent occupational disease of all (3).

\section{MATERIALS AND METHODS}

The authors analyzed data from the Czech National Registry of Occupational Diseases (National Institute of Public Health, NIPH) concerning main 6 diagnoses during 2008-2018.

Those diseases are under items

2.7 Diseases of peripheral nerves in the upper extremities in terms of ischaemic and compressive neuropathies due to work with vibrating tools and devices;

2.8 Diseases of bones and joints in the hands, wrists or elbows due to work with vibrating tools and devices;

2.9 Diseases of tendons, tendon capsules or insertions of muscles or joints in the extremities due to long-term and stereotyped overload;

2.10 Diseases of peripheral nerves in the extremities in term of compressive neuropathies due to long-term and stereotyped overload;

2.11 Diseases of bursae caused by local pressure;

2.12 Damage to the meniscus.

The authors' interest was to analyze the total number of persons (men and women) with these 6 diagnoses in individual years, age of persons at the time of recognition of occupational disease, 
Table 1. Crucial diagnostic criteria for recognition of selected occupational MSDs

\begin{tabular}{|l|l|}
\hline Disease & Criteria \\
\hline Synovitis and tenosynovitis & Chronic form of a minimum of 6-month duration \\
\hline Epicondylitis & $\begin{array}{l}\text { Chronic form of a minimum of 6-month duration } \\
\text { Positive orthopaedic examination } \\
\text { Positive result in the bone scintigraphy }\end{array}$ \\
\hline Impingement syndrome & Grade III, after surgery \\
\hline Arthrosis & $\begin{array}{l}\text { X-ray criterion: Grade III according to Kellgren \& Lawrence } \\
\text { Functional criterion: limitation of the movement range by more than one third }\end{array}$ \\
\hline Carpal tunnel syndrome & $\begin{array}{l}\text { Median nerve distal motoric latency (DML) } \geq 5.3 \mathrm{~ms} \\
\text { Median nerve sensory conduction velocity (SCV) } \leq 38 \mathrm{~m} / \mathrm{s}\end{array}$ \\
\hline Derangement of meniscus & Non-traumatic rupture of the dorsal half of the meniscus with blockade and unfavourable reaction of the joint \\
\hline
\end{tabular}

exposure duration and risk category of work officially recognized by public health inspection.

Diagnostic criteria for recognition of selected occupational MSDs are described in Table 1.

\section{Risk Factors Associated with MSDs}

The employer is legally obliged to deal with all working risk factors, including those which were proved to be associated with the occurrence of musculoskeletal disorders. The crucial step in the risk assessment is identification of workers who are exposed to a risk, e.g. the risk of MSDs, and grading of the risk. The officially implemented system of categorization of working operations classifies working activities into four categories according to the grade of risk (category $1-4$, category 4 is the worst). These factors include among others working posture, space parameters and arrangement of workplace, ergonomics of equipment and tools, total physical load at work, handling heavy loads, local muscular load (it means monotonous overload of particular structures of the locomotor system), repetitive type of work, type of work from the aspect of mental load (monotony, forced working pace, time pressure, shifting work, regime of work and rest), exposure to vibrations, adverse microclimatic conditions at work (cold, heat) and psychosocial factors (working climate and culture, workplace relationships, social support, job satisfaction) $(4,5)$.

\section{RESULTS}

Analyzed data from 2008 to 2018 (6,152 cases of recognized occupational musculoskeletal diseases in men and women together) in parameters: number of recognized occupational musculoskeletal diseases, number of selected recognized occupational musculoskeletal diseases (6 diagnoses) in individual years, age of persons at the time of recognition of occupational disease, exposure duration and risk category

Table 2. Incidence of selected recognized musculoskeletal occupational diseases in the Czech Republic during 2008-2018 $(N=6,152)$

\begin{tabular}{|c|c|c|c|c|c|c|c|c|c|c|c|c|}
\hline Disease & 2008 & 2009 & 2010 & 2011 & 2012 & 2013 & 2014 & 2015 & 2016 & 2017 & 2018 & Total \\
\hline $\begin{array}{l}2.7 \text { Diseases of peripheral nerves in the } \\
\text { upper extremities in terms of ischaemic and } \\
\text { compressive neuropathies due to work with } \\
\text { vibrating tools and devices }\end{array}$ & 144 & 161 & 170 & 172 & 149 & 108 & 115 & 121 & 158 & 165 & 141 & 1604 \\
\hline $\begin{array}{l}2.8 \text { Diseases of bones and joints in the hands, } \\
\text { wrists or elbows due to work with vibrating tools } \\
\text { and devices }\end{array}$ & 19 & 10 & 11 & 23 & 12 & 17 & 10 & 16 & 31 & 36 & 25 & 210 \\
\hline $\begin{array}{l}2.9 \text { Diseases of tendons, tendon capsules or } \\
\text { insertions of muscles or joints in the extremities } \\
\text { due to long-term and stereotyped overload }\end{array}$ & 187 & 162 & 164 & 142 & 101 & 95 & 125 & 122 & 166 & 189 & 186 & 1639 \\
\hline $\begin{array}{l}\text { 2.10 Diseases of peripheral nerves in the } \\
\text { extremities in terms of compressive neuropathies } \\
\text { due to long-term and stereotyped overload }\end{array}$ & 237 & 166 & 237 & 242 & 206 & 186 & 209 & 252 & 279 & 346 & 297 & 2657 \\
\hline $\begin{array}{l}2.11 \text { Diseases of bursae caused by local } \\
\text { pressure }\end{array}$ & 5 & 4 & 5 & 6 & 5 & 9 & 7 & 0 & 0 & 0 & 0 & 41 \\
\hline 2.12 Damage to the meniscus & 1 & 0 & 0 & 0 & 0 & 0 & 0 & 0 & 0 & 0 & 0 & 1 \\
\hline
\end{tabular}

Processed according to Occupational diseases in the Czech Republic (3). 
Table 3. Exposure time (median, years) of selected recognized musculoskeletal occupational diseases in the Czech Republic during 2008-2018

\begin{tabular}{|c|c|c|c|c|c|c|c|c|c|c|c|}
\hline Disease & 2008 & 2009 & 2010 & 2011 & 2012 & 2013 & 2014 & 2015 & 2016 & 2017 & 2018 \\
\hline $\begin{array}{l}2.7 \text { Diseases of peripheral nerves in the } \\
\text { upper extremities in terms of ischaemic and } \\
\text { compressive neuropathies due to work with } \\
\text { vibrating tools and devices }\end{array}$ & 8.00 & 9.67 & 9.46 & 11.00 & 9.50 & 10.00 & 10.00 & 8.00 & 8.00 & 6.00 & 3.83 \\
\hline $\begin{array}{l}2.8 \text { Diseases of bones and joints in the hands, } \\
\text { wrists or elbows due to work with vibrating tools } \\
\text { and devices }\end{array}$ & 14.00 & 13.00 & 11.00 & 17.50 & 18.50 & 6.17 & 17.00 & 21.50 & 9.67 & 11.20 & 7.49 \\
\hline $\begin{array}{l}2.9 \text { Diseases of tendons, tendon capsules or } \\
\text { insertions of muscles or joints in the extremities } \\
\text { due to long-term and stereotyped overload }\end{array}$ & 9.00 & 7.00 & 6.25 & 7.50 & 8.00 & 8.00 & 7.00 & 9.00 & 7.43 & 8.25 & 6.98 \\
\hline $\begin{array}{l}\text { 2.10 Diseases of peripheral nerves in the } \\
\text { extremities in terms of compressive neuropathies } \\
\text { due to long-term and stereotyped overload }\end{array}$ & 8.00 & 8.00 & 5.00 & 4.46 & 6.25 & 5.00 & 5.00 & 6.67 & 4.78 & 5.49 & 3.17 \\
\hline $\begin{array}{l}2.11 \text { Diseases of bursae caused by local } \\
\text { pressure }\end{array}$ & 10.00 & 3.00 & 10.00 & 16.75 & 7.00 & 20.00 & 5.25 & - & - & - & - \\
\hline 2.12 Damage to the meniscus & 13.00 & - & - & - & - & - & - & - & - & - & - \\
\hline
\end{tabular}

Processed according to Occupational diseases in the Czech Republic (3).

Table 4. Age (median, years) of persons with selected recognized musculoskeletal occupational diseases in the Czech Republic during 2008-2018

\begin{tabular}{|c|c|c|c|c|c|c|c|c|c|c|c|}
\hline Disease & 2008 & 2009 & 2010 & 2011 & 2012 & 2013 & 2014 & 2015 & 2016 & 2017 & 2018 \\
\hline $\begin{array}{l}2.7 \text { Diseases of peripheral nerves in the } \\
\text { upper extremities in terms of ischaemic and } \\
\text { compressive neuropathies due to work with } \\
\text { vibrating tools and devices }\end{array}$ & 51 & 51 & 49 & 51 & 50 & 50 & 50 & 51 & 50 & 49 & 50 \\
\hline $\begin{array}{l}2.8 \text { Diseases of bones and joints in the hands, } \\
\text { wrists or elbows due to work with vibrating tools } \\
\text { and devices }\end{array}$ & 54 & 56 & 53 & 54 & 55 & 50 & 52 & 55 & 52 & 53 & 55 \\
\hline $\begin{array}{l}2.9 \text { Diseases of tendons, tendon capsules or } \\
\text { insertions of muscles or joints in the extremities } \\
\text { due to long-term and stereotyped overload }\end{array}$ & 50 & 51 & 52 & 51 & 50 & 50 & 49 & 55 & 52 & 53 & 55 \\
\hline $\begin{array}{l}\text { 2.10 Diseases of peripheral nerves in the } \\
\text { extremities in terms of compressive neuropathies } \\
\text { due to long-term and stereotyped overload }\end{array}$ & 50 & 49 & 51 & 47 & 48 & 47 & 47 & 50 & 51 & 50 & 52 \\
\hline $\begin{array}{l}2.11 \text { Diseases of bursae caused by local } \\
\text { pressure }\end{array}$ & 55 & 56 & 55 & 53 & 43 & 53 & 50 & - & - & - & - \\
\hline 2.12 Damage to the meniscus & 40 & - & - & - & - & - & - & - & - & - & - \\
\hline
\end{tabular}

Processed according to Occupational diseases in the Czech Republic (3).

of work officially recognized by public health inspection are summarized in Tables 2, 3 and 4, and Figures 1, 2 and 3; 6,152 cases of 6 selected recognized occupational musculoskeletal diseases represent $47 \%$ of all recognized occupational diseases (13,034 cases) during the period from 2008-2018. The main proportion formed diseases of peripheral nerves in the extremities in terms of compressive neuropathies due to long-term and stereotyped overload (item $2.10 ; 2,657$ cases, $43 \%$ ), diseases of tendons, tendon capsules or insertions of muscles or joints in the extremities due to long-term and stereotyped overload (item 2.9; 1,639 cases,
$27 \%$ ) and diseases of peripheral nerves in the upper extremities in terms of ischaemic and compressive neuropathies due to work with vibrating tools and devices (item 2.7; 1,604 cases, 26\%).

\section{DISCUSSION}

Table 2 shows slight fluctuations in incidence for diagnoses under items $2.7-2.10$ in the period from 2008-2018, with no apparent trend to decline or increase. Items 2.11 and 2.12 can 


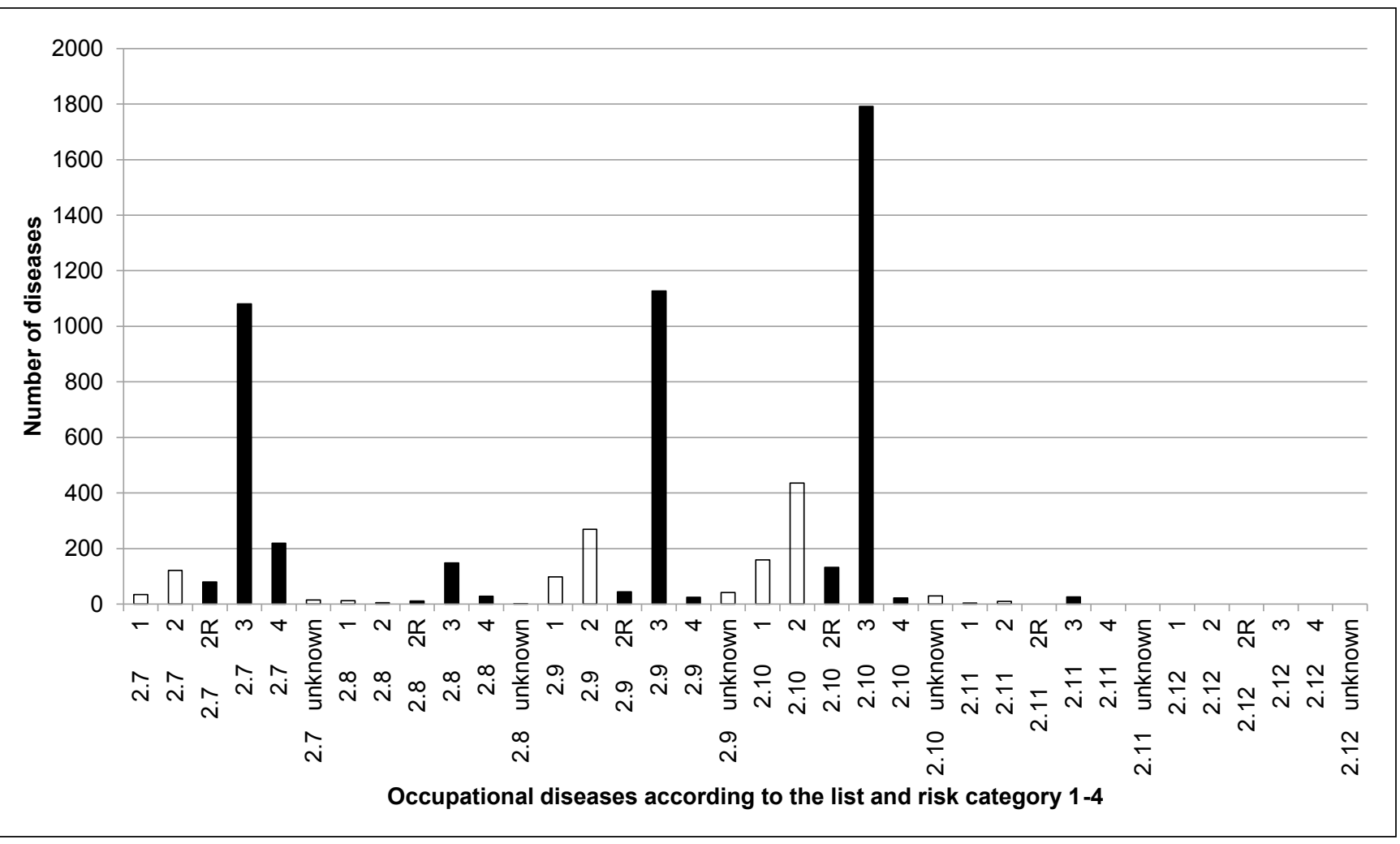

Fig. 1. Number of selected recognized musculoskeletal occupational diseases and working risk category in the Czech Republic during 2008-2018 (N=6,152).

Processed according to Occupational diseases in the Czech Republic (3).

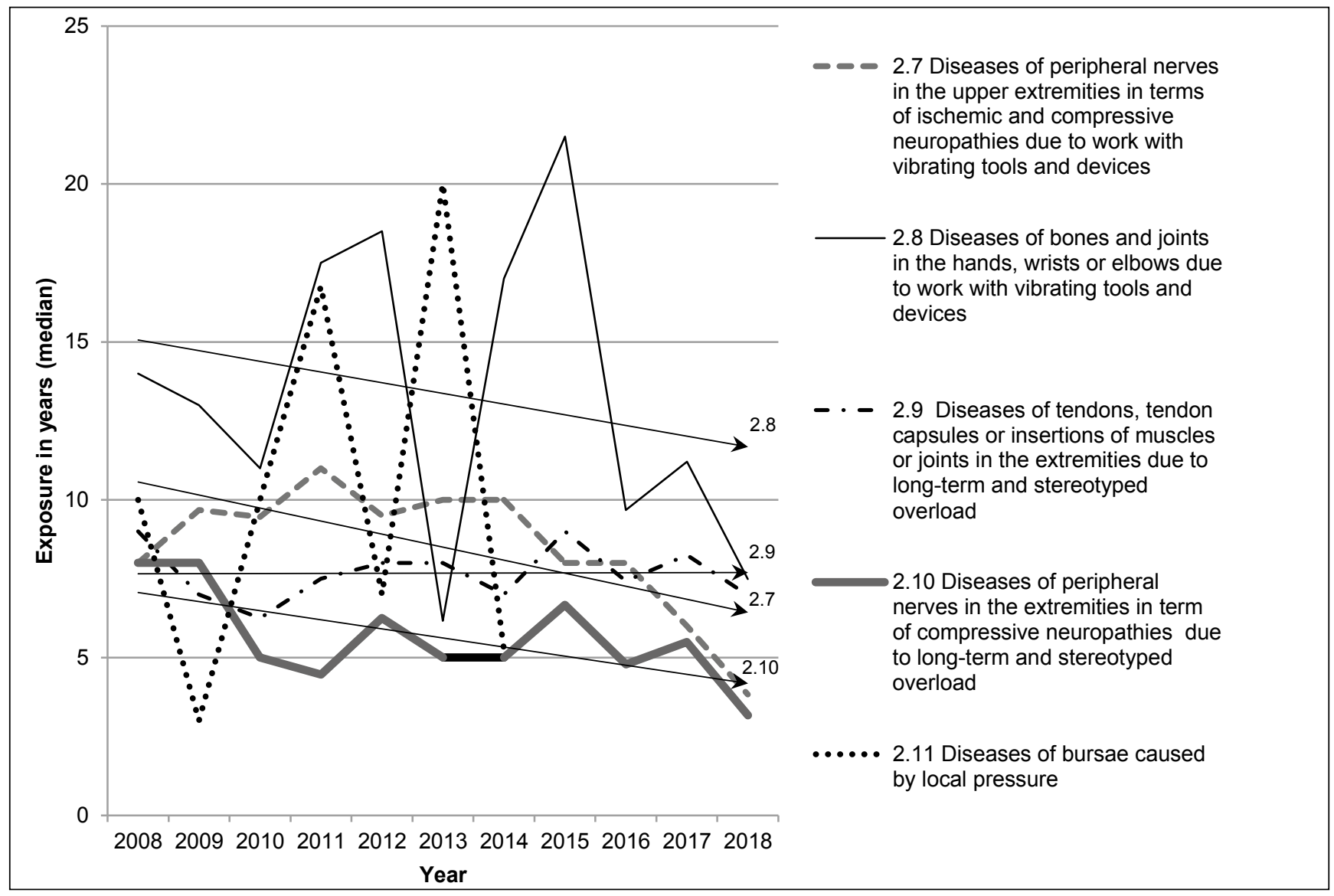

Fig. 2. Exposure time (median, years) of selected recognized musculoskeletal occupational diseases in the Czech Republic during 2008-2018.

Processed according to Occupational diseases in the Czech Republic (3). 


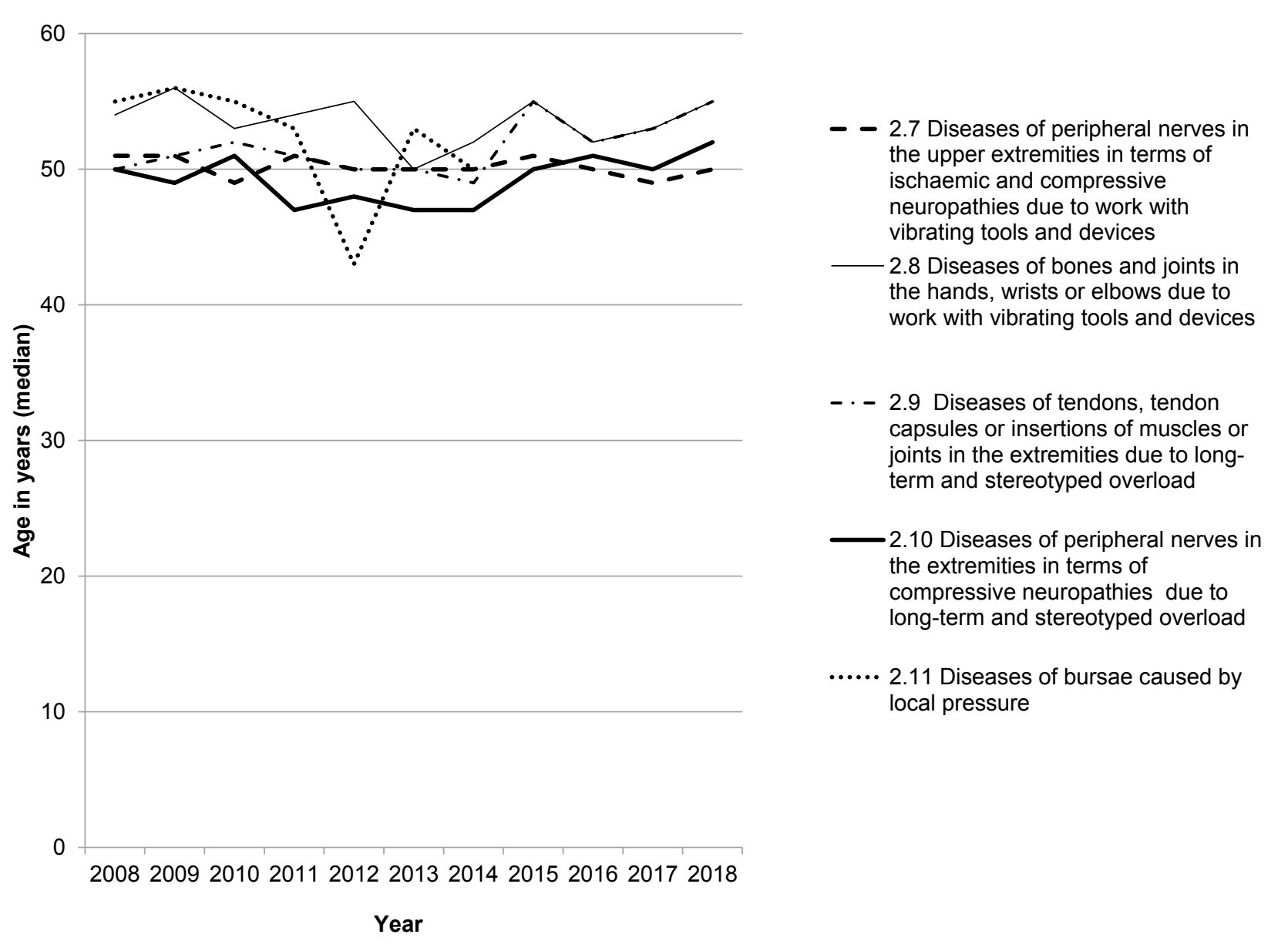

Fig. 3. Age (median, years) of persons with selected recognized musculoskeletal occupational diseases in the Czech Republic during 2008-2018.

Processed according to Occupational diseases in the Czech Republic (3).

be considered marginal because the disease has not occurred in the last 4 or 10 years of the reporting period (excluded from the list and assigned to item 2.9). While the age of persons in the individual years of the reporting period does not change, except for a single decrease in the median value in the items 2.11 (Table 4 and Fig. 3), the median value of the exposure time has tendency to decrease in 3 diagnoses (item 2.7, 2.8 and 2.10); this tendency is difficult to interpret other than as a result of increasing exposure to risk factors, especially to hand-arm vibration and long-term and stereotyped overload of the upper extremity (Table 3 and Fig. 2). The most prevalent risks in Europe are posture-related risks; they include tiring positions (43\% of workers are exposed a quarter or more of the time), lifting people $(10 \%)$, carrying heavy loads $(32 \%)$, repetitive movements (61\%), and vibrations (20\%) (6). It is also evident that the incidence of musculoskeletal disorders in the Czech Republic is due to risky work assessed in categories 3 (incl. 2R, which is border category between categories 2 and 3 according to exposure criteria) and 2 (Fig. 1), which is particularly evident in items 2.7, 2.9 and 2.10 and is related to overload of the musculoskeletal system of the upper extremities which does not correspond to the physiological possibilities of the organism of exposed persons. Prolonged exposure to biomechanical constraints in work situations is a major determinant of MSDs; targets of prevention must be excessively repetitive movements and intense physical effort, the handling of heavy loads, forced movements or prolonged uncomfortable postures, mechanical vibrations, and cold atmospheres. The psychological dimension of MSDs, as for all forms of chronic pain, is important too. Stress that in its origin is psychosocial disrupts activation of the muscles and reduces the efficiency of work-directed movements. Such stress also stimulates the mechanisms underlying inflammation and pain, reduces the capacity for tissue repair, and increases the likelihood of developing chronic pain. Psychosocial factors linked to work, such as strong psychological pressure associated with a weak level of autonomy, give rise to situations of "workplace tension", particularly in cases where workers lack support or recognition from their hierarchy (7).

\section{CONCLUSIONS}

With regard to the fact that occupational musculoskeletal diseases recently represent almost half of all occupational diseases in the Czech Republic, it is necessary to emphasize the principles of prevention of these diseases such a compli- 
ance of basic ergonomic criteria for workplaces, criteria and limits for total physical load in women and men based on physiological criteria, general limits for heavy load handling for men and women, specific criteria for youngsters, pregnant women, nursing mothers, and the mothers by the ninth months after delivery, limits for monotonous long-term overload of the locomotor system, especially of the upper extremities based on physiological criteria and limits for unphysiological working positions. A number of these principles are directly related to the technical provision of production, the organization of work and the regime of work and rest, the length of working hours and the setting of production standards, and generally to the work related stress.

\section{Acknowledgements}

Authors acknowledge Miss Petra Jandová for technical assistance when preparing data. The study was supported by the programme PROGRES Q29/LF1, Charles University, Prague.

\section{Conflict of Interests}

None declared

\section{REFERENCES}

1. European Agency for Safety and Health at Work. Work-related musculoskeletal disorders: prevalence, costs and demographics in the EU. Luxembourg: Publications Office of the European Union; 2019.

2. Tuček M. Introduction to occupational health. In: Bencko V, et al. Hygiene and epidemiology: selected chapters. 2nd ed. Prague: Karolinum Press; 2019. p. 111-24.

3. National Institute of Public Health. Occupational diseases in the Czech Republic [Internet]. Prague: NIPH [cited 2020 May 20]. Available from: http://www.szu.cz/publikace/data/nemoci-z-povolani-a-ohrozeni-nemociz-povolani-v-ceske-republice. (In Czech.)

4. Gauthy R. Musculoskeletal disorders: an ill-understood "pandemic". Brussels: ETUI-REHS; 2007.

5. Roquelaure Y. Musculoskeletal disorders and psychosocial factors at work. Report 142. Brussels: ETUI; 2018.

6. Eurofound; International Labour Organization. Working conditions in a global perspective. Luxembourg: Publications Office of the European Union; 2019.

7. Lang J, Ochsmann E, Kraus T, Lang JW. Psychosocial work stressors as antecedents of musculoskeletal problems: a systematic review and meta-analysis of stability adjusted longitudinal studies. Soc Sci Med. 2012;75(7):1163-74

Received March 17, 2020

Accepted in revised form May 20, 2020 